\title{
MODELING OF TEMPERATURE FIELD INSIDE THE TISSUE WITH A BLOOD VESSEL USING THE BEM-FDM ALGORITHM
}

\author{
Ewa Majchrzak ${ }^{1}$, Jolanta Borowska ${ }^{2}$, Joanna Klekot ${ }^{2}$, Damian Tarasek $^{3}$ \\ ${ }^{I}$ Institute of Computational Mechanics and Engineering, Silesian University of Technology \\ Gliwice, Poland \\ ${ }^{2}$ Institute of Mathematics, Czestochowa University of Technology, Czestochowa, Poland \\ ${ }^{3}$ Manchester Metropolitan University, Manchester, UK \\ ewa.majchrzak@polsl.pl,jolanta.borowska@im.pcz.pl,joanna.klekot@im.pcz.pl \\ d.tarasek@mmu.ac.uk
}

\begin{abstract}
The thermal interactions between the blood vessel and surrounding biological tissue are analyzed. The tissue temperature is described by the Pennes equation, while the equation determining the change of blood temperature along the blood vessel is formulated on the basis of adequate energy balance. These equations are coupled by a boundary condition given at the blood vessel wall. The problem is solved using the hybrid algorithm, this means the temperature field in biological tissue is determined by means of the boundary element method (BEM), while the blood temperature is determined by means of the finite difference method (FDM). In the final part the examples of computations are presented.
\end{abstract}

\section{Formulation of the problem}

The biological tissue is heated by one blood vessel [1-3] located at the central part of tissue cylinder. Assuming that the tissue temperature is changed only in the radial direction (as shown the calculations presented in the papers $[4,5]$ such an assumption is fully acceptable) the temperature field in the tissue sub-domain is described by the Pennes equation

$$
R_{1}<r<R_{2}: \frac{\lambda}{r} \frac{\mathrm{d}}{\mathrm{d} r}\left(r \frac{\mathrm{d} T(r)}{\mathrm{d} r}\right)+W_{B} c_{B}\left[T_{a}-T(r)\right]+Q_{m e t}=0
$$

where $r$ is the spatial co-ordinate, $R_{1}$ is the vessel radius, $R_{2}$ is the external radius of tissue sub-domain, $\lambda[\mathrm{W} /(\mathrm{mK})]$ is the constant thermal conductivity of tissue, $W_{B}$ $\left[\mathrm{kg} /\left(\mathrm{m}^{3} \mathrm{~s}\right)\right]$ is the blood perfusion rate, $c_{B}[\mathrm{~J} /(\mathrm{kgK})]$ is the blood specific heat, $Q_{m e t}$ $\left[\mathrm{W} / \mathrm{m}^{3}\right]$ is the metabolic heat source and $T_{a}$ is the arterial blood temperature.

It should be pointed out that the second component of this equation takes into account the presence of the capillaries in the tissue. 
On the wall of the blood vessel the Robin condition is assumed

$$
r=R_{1}: \quad \lambda \frac{\mathrm{d} T(r)}{\mathrm{d} r}=\alpha\left[T\left(R_{1}, z\right)-T_{B}(z)\right]
$$

where $\alpha\left[\mathrm{W} /\left(\mathrm{m}^{2} \mathrm{~K}\right)\right]$ is the heat transfer coefficient between the blood vessel and surrounding tissue, $T\left(R_{1}, z\right)$ is the temperature of vessel wall, while $T_{B}(z)$ is the blood temperature.

On the outer surface of the tissue the Dirichlet condition is accepted

$$
r=R_{2}: T\left(R_{2}, z\right)=T_{t}
$$

where $T_{t}$ is the known temperature.

Distribution of blood temperature $T_{B}(z)$ along the blood vessel is described by equation $[4,5]$

$$
0<z<Z: \quad \frac{\mathrm{d} T_{B}(z)}{\mathrm{d} z}=\frac{2 \alpha}{w c_{B} \rho_{B} R_{1}}\left[T\left(R_{1}, z\right)-T_{B}(z)\right]+\frac{Q_{B m e t}}{w c_{B} \rho_{B}}
$$

where $\rho_{B}\left[\mathrm{~kg} / \mathrm{m}^{3}\right]$ is the blood density, $w[\mathrm{~m} / \mathrm{s}]$ is the blood velocity, $Q_{B m e t}\left[\mathrm{~W} / \mathrm{m}^{3}\right]$ is the metabolic heat source.

Equation (4) is supplemented by initial condition: $T_{B}(0)=T_{B 0}$, this means that the inlet temperature $T_{B 0}$ of the blood vessel must be known.

As can be seen, the equations for biological tissue (1), (2) and vessel (4) are coupled by an unknown temperature $T_{w}=T\left(R_{1}, z\right)$.

\section{Method of solution}

The problem is solved using the hybrid algorithm, meaning the temperature field in biological tissue is determined by means of the BEM, while the blood temperature is determined by means of the FDM. Equation (1) can be written in the form

$$
\lambda r \frac{\mathrm{d}^{2} T}{\mathrm{~d} r^{2}}+\lambda \frac{\mathrm{d} T}{\mathrm{~d} r}-r k T+r Q=0
$$

where $k=W_{B} c_{B}$ and $Q=W_{B} c_{B} T_{a}+Q_{\text {met }}$.

The weighted residual criterion [6-8] for equation (5) is of the form

$$
\int_{R_{1}}^{R_{2}}\left[\lambda r \frac{\mathrm{d}^{2} T}{\mathrm{~d} r^{2}}+\lambda \frac{\mathrm{d} T}{\mathrm{~d} r}-r k T+r Q\right] T^{*}(\xi, r) \mathrm{d} r=0
$$


where $\xi$ is the observation point, $T^{*}(\xi, r)$ is the fundamental solution and it is a function of the form [9]

$$
T^{*}(\xi, r)=\frac{\operatorname{sgn}(r-\xi)}{2 \lambda}\left[\mathrm{I}_{0}\left(\sqrt{\frac{k}{\lambda}} \xi\right) \mathrm{K}_{0}\left(\sqrt{\frac{k}{\lambda}} r\right)-\mathrm{I}_{0}\left(\sqrt{\frac{k}{\lambda}} r\right) \mathrm{K}_{0}\left(\sqrt{\frac{k}{\lambda}} \xi\right)\right]
$$

where $I_{0}(\cdot)$ is the modified Bessel function of the first kind, zero order, while $\mathrm{K}_{0}$ $(\cdot)$ is the modified Bessel function of the second kind, zero order [10]. It can be checked that function (7) fulfills the equation

$$
\lambda r \frac{\partial^{2} T^{*}(\xi, r)}{\partial r^{2}}+\lambda \frac{\partial T^{*}(\xi, r)}{\partial r}-r k T^{*}(\xi, r)=-\delta(\xi, r)
$$

where $\delta(\xi, r)$ is the Dirac function.

Heat flux resulting from the fundamental solution is defined as follows

$$
q^{*}(\xi, r)=-\lambda \frac{\partial T^{*}(\xi, r)}{\partial r}
$$

this means

$$
q^{*}(\xi, r)=\frac{1}{2} \sqrt{\frac{k}{\lambda}} \operatorname{sgn}(r-\xi)\left[\mathrm{K}_{0}\left(\sqrt{\frac{k}{\lambda}} \xi\right) \mathrm{I}_{1}\left(\sqrt{\frac{k}{\lambda}} r\right)+\mathrm{K}_{1}\left(\sqrt{\frac{k}{\lambda}} r\right) \mathrm{I}_{0}\left(\sqrt{\frac{k}{\lambda}} \xi\right)\right]
$$

where for $(r-\xi)>0: \operatorname{sgn}(r-\xi)=1$, for $(r-\xi)<0: \operatorname{sgn}(r-\xi)=-1, \operatorname{sgn}(0)=0, \mathrm{I}_{1}$ $(\cdot)$ is the modified Bessel function of the first kind, first order, while $K_{1}(\cdot)$ is the modified Bessel function of the second kind, first order [10].

Twice integrating by parts of the first component of equation (6) one obtains

$$
\begin{gathered}
\quad\left[\lambda r \frac{\mathrm{d} T(r)}{\mathrm{d} r} T^{*}(\xi, r)-\lambda r \frac{\partial T^{*}(\xi, r)}{\partial r} T(r)\right]_{R_{1}}^{R_{2}}+Q \int_{R_{1}}^{R_{2}} r T^{*}(\xi, r) \mathrm{d} r+ \\
+\int_{R_{1}}^{R_{2}}\left(\lambda r \frac{\partial^{2} T^{*}(\xi, r)}{\partial r^{2}}+\lambda \frac{\partial T^{*}(\xi, r)}{\partial r}-r k T^{*}(\xi, r)\right) T(r) \mathrm{d} r=0
\end{gathered}
$$

Taking into account property (8) of fundamental solution one has

$$
\left[r q^{*}(\xi, r) T(r)-r T^{*}(\xi, r) q(r)\right]_{R_{1}}^{R_{2}}+Q \int_{R_{1}}^{R_{2}} r T^{*}(\xi, r) \mathrm{d} r-T(\xi)=0
$$

where $q(r)=-\lambda \mathrm{d} T(r) / \mathrm{d} r$. 
Equation (12) can be written in the form

$$
\begin{aligned}
T(\xi) & =R_{2} q^{*}\left(\xi, R_{2}\right) T\left(R_{2}\right)-R_{2} T^{*}\left(\xi, R_{2}\right) q\left(R_{2}\right)-R_{1} q^{*}\left(\xi, R_{1}\right) T\left(R_{1}\right)+ \\
& +R_{1} T^{*}\left(\xi, R_{1}\right) q\left(R_{1}\right)+Q \int_{R_{1}}^{R_{2}} r T^{*}(\xi, r) \mathrm{d} r
\end{aligned}
$$

For $\xi \rightarrow R_{1}$ and $\xi \rightarrow R_{2}$ one obtains

$$
\begin{aligned}
& \frac{1}{2} T\left(R_{1}\right)=R_{2} q^{*}\left(R_{1}, R_{2}\right) T\left(R_{2}\right)-R_{2} T^{*}\left(R_{1}, R_{2}\right) q\left(R_{2}\right)- \\
& R_{1} q^{*}\left(R_{1}, R_{1}\right) T\left(R_{1}\right)+R_{1} T^{*}\left(R_{1}, R_{1}\right) q\left(R_{1}\right)+Q \int_{R_{1}}^{R_{2}} r T^{*}\left(R_{1}, r\right) \mathrm{d} r \\
& \frac{1}{2} T\left(R_{2}\right)=R_{2} q^{*}\left(R_{2}, R_{2}\right) T\left(R_{2}\right)-R_{2} T^{*}\left(R_{2}, R_{2}\right) q\left(R_{2}\right)- \\
& R_{1} q^{*}\left(R_{2}, R_{1}\right) T\left(R_{1}\right)+R_{1} T^{*}\left(R_{2}, R_{1}\right) q\left(R_{1}\right)+Q \int_{R_{1}}^{R_{2}} r T^{*}\left(R_{2}, r\right) \mathrm{d} r
\end{aligned}
$$

The system of equations (14), (15) can be written in the matrix form

$$
\begin{gathered}
{\left[\begin{array}{ll}
-R_{1} T^{*}\left(R_{1}, R_{1}\right) & R_{2} T^{*}\left(R_{1}, R_{2}\right) \\
-R_{1} T^{*}\left(R_{2}, R_{1}\right) & R_{2} T^{*}\left(R_{2}, R_{2}\right)
\end{array}\right]\left[\begin{array}{l}
q\left(R_{1}\right) \\
q\left(R_{2}\right)
\end{array}\right]=} \\
{\left[\begin{array}{ll}
-R_{1} q^{*}\left(R_{1}, R_{1}\right)-\frac{1}{2} & R_{2} q^{*}\left(R_{1}, R_{2}\right) \\
-R_{1} q^{*}\left(R_{2}, R_{1}\right) & R_{2} q^{*}\left(R_{2}, R_{2}\right)-\frac{1}{2}
\end{array}\right]\left[\begin{array}{l}
T\left(R_{1}\right) \\
T\left(R_{2}\right)
\end{array}\right]+Q\left[\begin{array}{l}
\int_{R_{1}}^{R_{2}} r T^{*}\left(R_{1}, r\right) \mathrm{d} r \\
\int_{R_{1}}^{R_{2}} r T^{*}\left(R_{2}, r\right) \mathrm{d} r
\end{array}\right]}
\end{gathered}
$$

or

$$
\left[\begin{array}{ll}
G_{11} & G_{12} \\
G_{21} & G_{22}
\end{array}\right]\left[\begin{array}{l}
q\left(R_{1}\right) \\
q\left(R_{2}\right)
\end{array}\right]=\left[\begin{array}{ll}
H_{11} & H_{12} \\
H_{21} & H_{22}
\end{array}\right]\left[\begin{array}{l}
T\left(R_{1}\right) \\
T\left(R_{2}\right)
\end{array}\right]+Q\left[\begin{array}{l}
Z_{1} \\
Z_{2}
\end{array}\right]
$$

Introducing the boundary conditions (2), (3) into the system of equations (17) one has

$$
\left[\begin{array}{ll}
G_{11} & G_{12} \\
G_{21} & G_{22}
\end{array}\right]\left[\begin{array}{c}
-\alpha\left[T\left(R_{1}, z\right)-T_{B}(z)\right] \\
q\left(R_{2}, z\right)
\end{array}\right]=\left[\begin{array}{cc}
H_{11} & H_{12} \\
H_{21} & H_{22}
\end{array}\right]\left[\begin{array}{c}
T\left(R_{1}, z\right) \\
T_{t}
\end{array}\right]+Q\left[\begin{array}{l}
Z_{1} \\
Z_{2}
\end{array}\right]
$$


or

$$
\left[\begin{array}{cc}
-\alpha G_{11}-H_{11} & G_{12} \\
-\alpha G_{21}-H_{21} & G_{22}
\end{array}\right]\left[\begin{array}{l}
T\left(R_{1}, z\right) \\
q\left(R_{2}, z\right)
\end{array}\right]=\left[\begin{array}{l}
H_{12} T_{t}-\alpha G_{11} T_{B}(z)+Q Z_{1} \\
H_{22} T_{t}-\alpha G_{21} T_{B}(z)+Q Z_{2}
\end{array}\right]
$$

Under the assumption that $T_{B}(z)$ is known, this system of equations allows one to determine the values of $T\left(R_{1}, z\right)$ and $q\left(R_{2}, z\right)$ and next

$$
q\left(R_{1}, z\right)=-\alpha\left[T\left(R_{1}, z\right)-T_{B}(z)\right]
$$

The temperatures at the internal points are calculated using the formula

$$
\begin{aligned}
& T\left(\xi_{i}, z\right)=R_{2} q^{*}\left(\xi_{i}, R_{2}\right) T_{t}-R_{2} T^{*}\left(\xi_{i}, R_{2}\right) q\left(R_{2}, z\right)-R_{1} q^{*}\left(\xi_{i}, R_{1}\right) T\left(R_{1}, z\right)+ \\
& +R_{1} T^{*}\left(\xi_{i}, R_{1}\right) q\left(R_{1}, z\right)+Q \int_{R_{1}}^{R_{2}} r T^{*}\left(\xi_{i}, r\right) \mathrm{d} r
\end{aligned}
$$

As mentioned above, to solve the system of equations (19) the blood temperature $T_{B}(z)$ must be known. This temperature is calculated from the equation (4) which can be written as

$$
0<z<Z: \quad \frac{\mathrm{d} T_{B}(z)}{\mathrm{dz}}=A\left[T_{w}(z)-T_{B}(z)\right]+B
$$

where

$$
A=\frac{2 \alpha}{c_{B} \rho_{B} w R_{1}}, \quad B=\frac{Q_{\text {Bmet }}}{c_{B} \rho_{B} w}
$$

The following discretization of variable $z$ is introduced

$$
0=z_{0}<z_{1}<\ldots<z_{j-1}<z_{j}<z_{j+1}<\ldots<z_{m}=Z
$$

where $z_{j}=j h, h$ is the mesh step and $j=0,1,2, \ldots, m$.

The approximation of equation (22) takes the form

$$
\frac{T_{B j+1}-T_{B j}}{h}=A\left(T_{0 j}-T_{B j}\right)+B
$$

and then

$$
T_{B j+1}=(1-A h) T_{B j}+A h T_{0 j}+B h
$$

where $T_{0 j}$ denotes the vessel wall temperature for $z=z_{j}$, as shown in Figure 1 . 
Summing up, for $j=0$ the system of equations (19), where the temperature $T_{B}(0)=T_{B 0}$ is known, should be solved. Then on the right-hand side of equation (26) for $j=0$ the temperatures $T_{00}=T\left(R_{1}, 0\right)$ and also $T_{B 0}$ are known. Using this equation the temperature $T_{B 1}$ is calculated. Next, the system of equations (19), where $T_{B}(\mathrm{z})=T_{B 1}(z=h)$ is known, is solved and the temperature $T_{B 2}$ from formula (26) is determined etc.

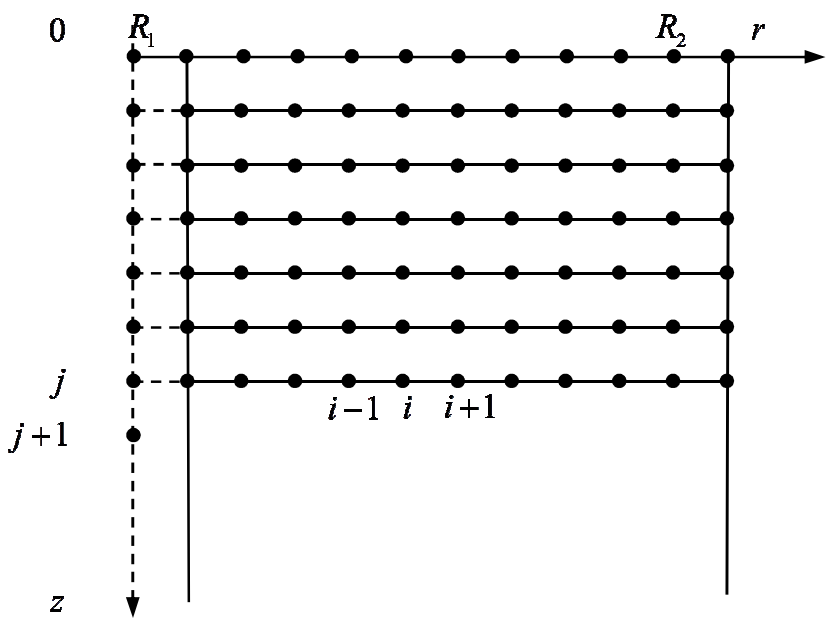

Fig. 1. Discretization

\section{Results of computations}

In the computations the following input data are assumed: thermal conductivity of tissue $\lambda=0.5 \mathrm{~W} /(\mathrm{mK})$, specific heat of blood $c_{B}=3900 \mathrm{~J} /(\mathrm{kgK})$, density of blood $\rho_{B}=1060 \mathrm{~kg} / \mathrm{m}^{3}$, blood perfusion rate $W_{B}=G_{B} \rho_{B}=10 \mathrm{~kg} /\left(\mathrm{m}^{3} \mathrm{~s}\right)$, arterial blood temperature $T_{a}=37^{\circ} \mathrm{C}$. The metabolic heat sources for tissue and blood are equal to $Q_{m e t}=1000 \mathrm{~W} / \mathrm{m}^{3}, Q_{B m e t}=500 \mathrm{~W} / \mathrm{m}^{3}$. The radius of blood vessel is equal to $R_{1}=0.002 \mathrm{~m}$ and the outer radius of the tissue surrounding the blood vessel equals to $R_{2}=10 R_{1}$. On the basis of the Nusselt number $(\mathrm{Nu}=4)$ and the Peclet number $(\mathrm{Pe}=100)[11,12]$, the heat transfer coefficient $\alpha=500 \mathrm{~W} /\left(\mathrm{m}^{2} \mathrm{~K}\right)$ and the blood velocity $w=0.003 \mathrm{~m} / \mathrm{s}$ are determined, respectively. The entry blood temperature for $z=0$ is assumed as $T_{B 0}=37^{\circ} \mathrm{C}$. On the outer surface of the tissue surrounding the blood vessel $T_{t}=37^{\circ} \mathrm{C}$.

The domain of tissue has been divided into 10 internal cells (c.f. Fig. 1), the mesh step $h=R_{1}=0.002 \mathrm{~m}$ (c.f. equation (26)).

In Figure 2 the temperature distribution in the tissue domain for $z=0.01 \mathrm{~m}$, $0.02,0.03,0.04$ and $0.05 \mathrm{~m}$ is presented, while Figure 3 illustrates the course of blood temperature along the blood vessel. 


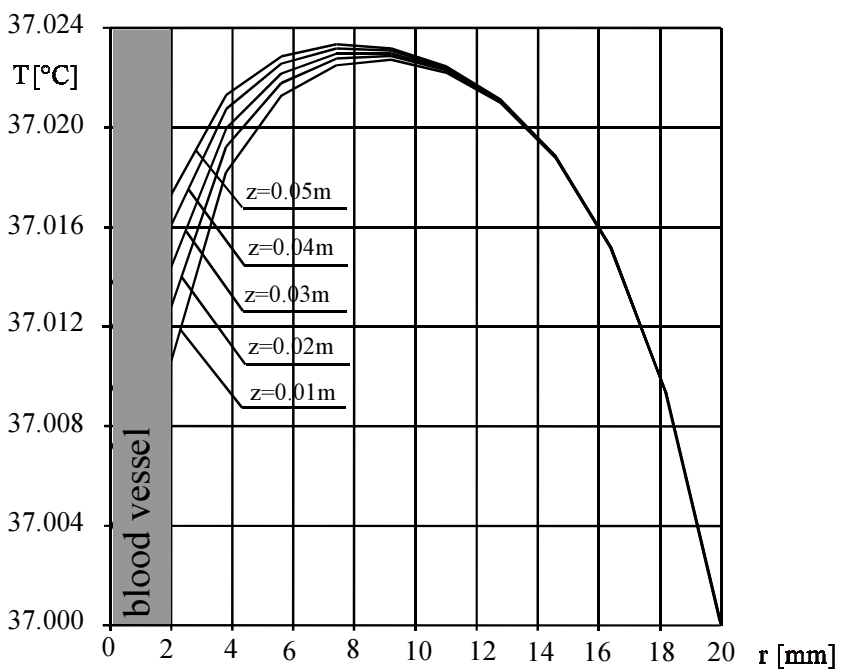

Fig. 2. Temperature distribution for different values of $z$

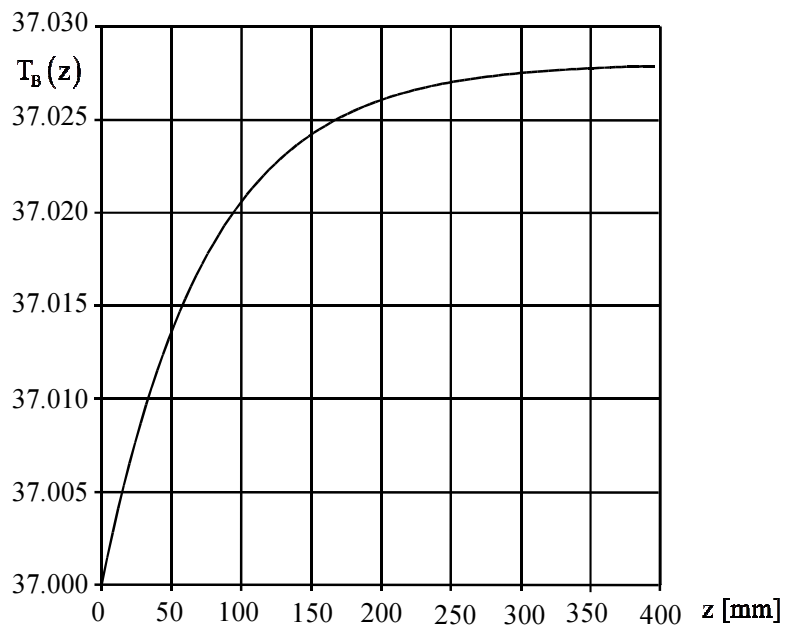

Fig. 3. Blood temperature

\section{Conclusions}

The thermal interactions between blood vessel and tissue have been considered. The temperature distribution has been obtained using the hybrid algorithm. The results have been compared with the analytical solution presented in [9] and they were practically the same. The algorithm proposed allows one, among others, to determine the equilibrium in the length of the blood vessel. 


\section{References}

[1] Chato J., Heat transfer to blood vessels, Journal of Biomechanical Engineering 1980, 5, 102, 110-118.

[2] Huang H.W., Chan C.L., Roemer R.B., Analytical solutions of Pennes bio-heat transfer equation with a blood vessel, Journal of Biomechanical Engineering 1994, 116, 208-212.

[3] Shivastava D., Roemer R.B., Readressing the issue of thermally significant blood vessels using a countercurrent vessel network, Journal of Biomechanical Engineering 2006, 128, 210-216.

[4] Majchrzak E., Mochnacki B., Numerical model of heat transfer between blood vessel and biological tissue, Computer Assisted Mechanics and Engineering Sciences 1999, 6, 439-447.

[5] Majchrzak E., Mochnacki B., Analysis of bio-heat transfer in the system of blood vesselbiological tissue, Kluwer Academic Publishers 2001, 201-211.

[6] Brebbia C.A., Telles J.C.F., Wrobel L.C., Boundary Element Techniques, Springer-Verlag, Berlin, New York 1984.

[7] Majchrzak E., Metoda elementów brzegowych w przepływie ciepła, Wyd. Pol. Częstochowskiej, Częstochowa 2001.

[8] Klekot J., Boundary element method for elliptic equation - determination of fundamental solution, Scientific Research of the Institute of Mathematics and Computer Science 2010, 1(9), 61-70.

[9] Borowska J., Klekot J., Deternination of fundamental solution for diffusion equation in cylindrical co-ordinate system with temperature-dependent source term, Scientific Research of the Institute of Mathematics and Computer Science 2012, 2(11), 15-24.

[10] Polyanin A.D., Manzhirov A.V., Handbook of Mathematics for Engineers and Scientists, Chapman \& Hall/CRC Press 2007.

[11] Majchrzak E., Tarasek D., Numerical modelling of heat transfer in a single blood vessel and surrounding biological tissue, Scientific Research of the Institute of Mathematics and Computer Science 2010, 2(9), 145-152.

[12] Majchrzak E., Modelowanie i analiza zjawisk termicznych, Część IV, [in:] Mechanika techniczna, Tom XII: Biomechanika, ed. R. Będziński, IPPT PAN, Warszawa 2011, 223-361. 